NBER WORKING PAPER SERIES

\title{
OUTSOURCING TARIFF EVASION: A NEW EXPLANATION FOR ENTREPOT TRADE
}

\author{
Raymond Fisman \\ Peter Moustakerski \\ Shang-Jin Wei \\ Working Paper 12818 \\ http://www.nber.org/papers/w12818
}

\author{
NATIONAL BUREAU OF ECONOMIC RESEARCH \\ 1050 Massachusetts Avenue \\ Cambridge, MA 02138 \\ January 2007
}

\begin{abstract}
* Associate Professor, 823 Uris Hall, Graduate School of Business, Columbia University, New York, NY 10027, phone: (212) 854-9157; fax: (212) 854-9895; email:rf250@ columbia.edu. **Senior Associate, Booz Allen Hamilton, 101 Park Avenue, New York, NY 10178, phone: (212) 551-6798, fax: (212) 551-6732, email: moustakerski_peter@bah.com*** Assistant Director and Chief of the Trade and Investment Division, Research Department, IMF, 700 19th Street NW, Washington, DC 20431, and Research Associate and Director of the Working Group on the Chinese Economy, National Bureau of Economic Research, phone: 202/797-6023, fax: 202/797-6181, swei@imf.org. www.nber.org/ wei. We thank Jahangir Aziz, Lee Branstetter, Mihir Desai, Martin Feldstein, Wensheng Peng, John Romalis, and participants at NBER and CEPR conferences and a World Bank-IMF joint seminar for helpful comments and Yuanyuan Chen for able research assistance. The views expressed herein are those of the author(s) and do not necessarily reflect the views of the National Bureau of Economic Research.

(C) 2007 by Raymond Fisman, Peter Moustakerski, and Shang-Jin Wei. All rights reserved. Short sections of text, not to exceed two paragraphs, may be quoted without explicit permission provided that full credit, including $\odot$ notice, is given to the source.
\end{abstract}


Outsourcing Tariff Evasion: A New Explanation for Entrepot Trade

Raymond Fisman, Peter Moustakerski, and Shang-Jin Wei

NBER Working Paper No. 12818

January 2007

JEL No. F1,O10,O17

\section{$\underline{\text { ABSTRACT }}$}

Traditional explanations for indirect trade through an entrepot have focused on savings in transport costs and on the role of specialized agents in processing and distribution. We provide an alternative perspective based on the possibility that entrepots may facilitate tariff evasion. Using data on direct exports to mainland China and indirect exports via Hong Kong SAR, we find that the indirect export rate rises with the Chinese tariff rate, even though there is no legal tax advantage to sending goods via Hong Kong SAR. We undertake a number of extensions to rule out plausible alternative hypotheses based on existing explanations for entrepot trade.

Raymond Fisman

School of Business

Columbia University

823 Uris Hall

3022 Broadway

New York, NY 10027

and NBER

rf250@columbia.edu

Peter Moustakerski

Booz Allen Hamilton

moustakerski_peter@bah.com
Shang-Jin Wei

International Monetary Fund

Room 10-700

19th Street, NW

Washington, DC 20433

and NBER

swei@imf.org 


\section{Introduction}

Indirect trade through an entrepôt is a common phenomenon in world commerce. For example, for every $\$ 100$ that the United States exports to mainland China, approximately $\$ 23$ goes through Hong Kong SAR. Globally, indirect trade as a share of the total trade is estimated to be around 17 percent (Andriamananjara, Arce, and Ferrantino, 2004). There are thirty-some countries that are involved in a significant amount of indirect trade. Macao, Cyprus, Fiji, Senegal, Jordan, Armenia, Seychelles, Honduras, Benin, Montserrat, St. Lucia, and Singapore are some of the other prominent entrepôts through which indirect trade takes place.

Explanations in the literature for this high volume of indirect trade have focused on the presence of specialized agents that match buyers and sellers across markets (Feenstra and Hanson, 2004) and the economization of transport costs, which has a similar rationale to the hub-and-spoke pattern in airline traffic (Andriamananjara, Arce, and Ferrantino, 2004). These factors are undoubtedly responsible at least in part for the high rates of indirect trade. However, we propose an alternative, previously undocumented explanation in this paper: the use of entrepôt economies to facilitate tariff evasion. As in the traditional argument for indirect trade, the evasion-based explanation also posits a role for specialized agents that are better positioned to transport goods to their final destinations: In our explanation, the agents' advantage is in transporting goods without paying the required tariffs. We suspect that the evasion-motivated indirect trade is likely to be particularly important for exports to countries with high tariffs and weak public governance.

This explanation has been made casually in the policy arena; most recently, the UNCTAD Trade and Development Report (2005) speculates that tariff evasion may be responsible for the rise in entrepôt trade. Further, there are also anecdotal accounts of this role of trade intermediaries. For example, a report from the United States Department of Agriculture, describes the "unofficial channels" that are used to export food products to China: "Using unofficial channels, to bring in a 40 foot container of imported fresh fruit from Hong Kong to one of the cities in the Pearl River Delta costs approximately $\$ 4,000$ to $\$ 6,000 \ldots$ This amount is usually much less than the price paid when using official channels." (USDA, 1997). However, there exists no systematic evidence on the use of entrepôt trade for tariff evasion purposes.

We provide a quantitative examination of this hypothesis in the context of the Hong Kong SAR, the world's largest entrepôt economy, where trade was 259 percent of GDP in 1998 
(Feenstra and Hanson, 2004), and a common stopping point for goods both entering and leaving from mainland China. Since Hong Kong is legally a separate customs area, China applied exactly the same tariff schedule on imports from Hong Kong as those from any other economy in the world during our sample period. In other words, there is no legal tax advantage of sending goods to China via Hong Kong. ${ }^{1}$

Over the last ten years, Chinese tariff rates have been declining steadily, from an average rate of 23.6 percent in 1996 to 15.8 percent by 2001. During the same period, the average fraction of the rest of the world's exports to China that goes through Hong Kong SAR has also been on the decline, from 26 percent in 1996 to 20 percent in 2001 (see Table 1 for details). These aggregated statistics are consistent with the tariff evasion explanation for the indirect trade, though many other explanations are also consistent with this aggregate picture.

This paper builds a case for the evasion hypothesis using disaggregated data on indirect exports to China via Hong Kong SAR. Tariff evasion, by its very nature, is not directly observable. We are thus required to take an indirect approach in testing any hypothesis related to evasion. The methodology we use in this paper is straightforward. On a product by product basis, we compute indirect trade intensity - the ratio of indirect exports to China going through Hong Kong SAR to total exports to China - and examine if it has any systematic relationship with product-level tariff rates. The benefit of indirect trade for the purposes of evading tariffs is increasing in the value of tariffs evaded, and hence the tariff rate ${ }^{2}$. As there is no preferential tariff treatment for indirect trade via Hong Kong SAR (or elsewhere), this forms the basis for our test of our 'outsourcing evasion' hypothesis. With disaggregated data (at HS 6-digit level) for the years 1996-2001, we find a clear positive association between tariff rate and intensity of indirect trade. This is consistent with the hypothesis that part of the role of the middlemen is to help evade tariff payments.

The use of indirect trade may be correlated with a good's need to be intermediated (for example, products with lower demand elasticities may be more likely to be transshipped). This is problematic if the latter is correlated with the tariff structure, leading to a spurious correlation between indirect trade intensity and tariff level. We therefore extend the analysis by adding 6-digit HS fixed effects and also by differencing the data. This effectively deals with any characteristics

\footnotetext{
${ }^{1}$ Since January 1, 2004 (outside our sample), China has reduced tariff rates to zero on many direct imports from Hong Kong. MFN rates continue to apply to indirect imports from other countries passing through Hong Kong.

${ }^{2}$ If we assume that the potential punishment does not increase linearly (see, for example, Slemrod and Yitzhaki, 2002), we expect the rate of transshipping (relative to direct shipment) to be increasing in the tariff rate - there is a greater incentive to evade tariffs on high tariff goods.
} 
of imports that are not time-varying. We find that the results remain statistically significant at the one percent level, though the point estimates are somewhat reduced.

We provide several additional robustness tests of our results. First, we look at sectors for which most importers receive legal tariff exemptions. Since there is little evasion-related motivation reason to undertake indirect trade in such industries, we do not expect to observe any correlation between tariffs and indirect export intensity; this is borne out by the data, as we do not find any tariff-indirect trade correlation for this set of products in our data.

We provide two additional tests that specifically address alternative explanations based on the two traditional rationales for indirect trade. To examine whether specialized knowledge may be responsible for our results, we examine trade in homogeneous and differentiated products separately based on the Rauch (1999) classification. This is based on the idea that there may be economic rationales, unrelated to evasion, for trade in differentiated products to go through an entrepôt, as a middleman's specialized knowledge on a differentiated product could help to mediate the trade. Indeed, Feenstra and Hanson (2004) suggest that Hong Kong may play an important intermediary role for differentiated products, since such products may require greater quality sorting. In contrast, there may be less specialized product-specific knowledge involved for trade in homogenous products. We find a positive correlation between tariff rate and indirect trade intensity for both homogenous and differentiated products. This further bolsters our interpretation that tariff evasion is a significant motivation for the observed indirect trade. Second, to assess the credibility of explanations based on transport costs, we include a control for total trade volume (a loose proxy for shipment size). This also does not affect our basic results.

We provide an illustrative calculation to get a sense of quantitative importance of evasioninduced indirect trade. According to one specification that we present below, a ten percent increase in tariff rate would lead to an increase in the indirect trade rate by 2.9 percentage points. Thus, an increase in the tariff rate from zero to 19 percent (the average statutory tariff rate in China in 2001) would lead to an indirect export rate of about 5.5 percent, suggesting that about a quarter of the indirect exports through Hong Kong may be accounted for by evasion motivations.

It is important to note that the paper does not call into question the integrity of the Hong Kong customs nor the reliability of Hong Kong statistics. In fact, the paper relies on the accuracy of the Hong Kong customs' statistics to make the analysis meaningful. 
In addition to bringing new insight to the literature on indirect trade, we also contribute to the growing empirical literature on tax evasion and smuggling. Relevant theoretic work and earlier empirical research are discussed in Slemrod and Yitzhaki (2000). A recent paper by Fisman and Wei (2004) provided an estimate of the responsiveness of tax evasion at the Chinese borders to Chinese tariff rates. The current paper differs from Fisman and Wei (2004) in several important ways. Fist, while the earlier paper addresses a public finance question- the elasticity of evasion to tax rates, the current paper investigates a trade question - whether the prevalent entrepôt trade phenomenon in the world commerce could be explained by tariff evasion. Second, the earlier paper does not automatically imply the result in this paper: It is logically possible that entrepôt trade is unrelated to evasion even if there is evasion at the Chinese border. The earlier paper, however, is a necessary condition: the Chinese border has to be corruptible for Hong Kong to serve as an intermediate step to evade tariffs.

The rest of this paper proceeds as follows. Section 2 provides a conceptual framework. Section 3 describes the datasets brought together for this research. Section 4 presents our estimation strategy and results. Section 5 concludes.

\section{Empirical Framework}

For expositional purposes, we assume in this section that tariffs may only be evaded by routing goods through Hong Kong and that traders are risk-neutral. For simplicity, we assume every trader exports a fixed amount, V. We describe the cost-benefit trade-off associated with evasion for a typical trader $\mathrm{k}$ in industry $\mathrm{i}$ as being given by:

$$
\begin{aligned}
& \text { Benefit }_{\mathrm{ik}}=\tau_{\mathrm{i}} \mathrm{V} \\
& \text { Cost }_{\mathrm{ik}}=\mathrm{C}+\gamma \tau_{\mathrm{i}} \mathrm{V}+\eta_{\mathrm{ik}}
\end{aligned}
$$

Here, $\tau_{\mathrm{i}}$ is the tariff rate for industry $\mathrm{i}$. The cost includes a fixed, a variable and a random component: $\mathrm{C}$ is the fixed cost; $\gamma<1$ describes the variable cost; $\eta_{\mathrm{ik}}$ represents the random component, which is realized before the trade makes the decision. A representative trader (of good i) would choose to evade if and only if the benefit of doing so exceeds the cost, or 
$\eta_{\mathrm{ik}} \leq(1-\gamma) \tau_{\mathrm{i}} \mathrm{V}-\mathrm{C}$

Assuming that $\eta_{\mathrm{ik}}$ is i.i.d. across all traders and has a cumulative distribution function $\mathrm{F}$, then the fraction of exports in industry $i$ that may be re-routed to Hong Kong to evade tariffs is given by:

(1) (Indirect Export Rate) $)_{\mathrm{i}}=\mathrm{F}\left((1-\gamma) \tau_{\mathrm{i}} \mathrm{V}-\mathrm{C}\right)$

If we further assume that $\mathrm{F}$ has a uniform distribution, we may express this as a linear regression:

(2) $(\text { Indirect Export Rate) })_{\mathrm{i}}=\alpha+\beta^{*} \tau_{\mathrm{i}}+\varepsilon_{\mathrm{i}}$, where $\beta>0$

Intuitively, if it is relatively inexpensive to evade tariffs by using Hong Kong as an entrepôt, a larger fraction of trade will be routed through Hong Kong if the tariff rate is higher. ${ }^{3}$

If the random cost, $\eta_{\mathrm{ik}}$, does not follow a uniform distribution, or if the cost of evasion is non-linear in the tariff rate, then the indirect trade rate may be a non-linear function of the tariff rate.

\section{Data}

Three pieces of data are crucial for our empirical tests: (a) Chinese tariffs, (b) direct exports to China at a product level, and (c) indirect exports to China via Hong Kong at a product level. ${ }^{4}$

The data on Chinese tariffs are taken from the World Bank's World Integrated Trade Solution (WITS) database, derived from the UNCTAD TRAINS (Trade Analysis and Information System) database, which gives tariff rates at the 8-digit HS level. Since our import/export data are

\footnotetext{
${ }^{3}$ This paper has not formally examined the issue of possible endogeneity of the tariff rate. If the government were to set the tariff rates with revenue maximization in mind, it may set relatively high rates on products that are somehow physically more difficult to evade tariff, then the true effect of tariff on indirect trade would be even bigger than documented here.

${ }^{4}$ It is these data requirements that preclude the expansion of our analyses to a broader set of countries. First, the UNCTAD TRAINS database described below has significant gaps for many countries. Second, we require data on reexports as reported by the entrepôt country itself, since data on re-exports generally do not list the intermediate country.
} 
at the 6-digit level, we need to aggregate tariff rates up to the 6-digit level. As there is relatively little variation in tax rates at the 8-digit level within a 6-digit category, we are able to restrict ourselves to the sample for which there are uniform rates at this level of aggregation.

The earliest year for which we have detailed data on tariffs is 1996, and our data reflect year-end tariff rates. Since the import and export data are cumulated for the entire year, matching imports with the appropriate tax rates is complicated by mid-year changes in the tariff structure. There were no tariff changes in 1996. In 1997, tariffs were changed on October 1st for this year, we take a weighted average of year-end 1996 and 1997 tariffs as our measure of the 1997 tariff rate. Since the tariff changes of 1998-2001 were all implemented on January 1, the tariff rate is uniform throughout those years. We define Tariff $i$ as the tariff rate on incoming goods in industry $i$ in year $t$.

To calculate our indirect export rate, we require countries' own reports of direct exports to China, as well as Hong Kong's reports of indirect exports. The direct export data come from WITS, which in turn gets its export statistics from the United Nations' Comtrade database. These data are collected by the United Nations Statistical Division from individual countries' trade records, and include information on imports and exports for each country, recorded according to the 6-digit Harmonized Commodity Description and Coding System (HS). For most of our regressions, we focus on countries where export data are available for the entire period, and further omit Africa and the Middle East because of very low export rates. This yields a final set of the 29 countries listed in appendix Table A1. We define Direct_exports ict $_{\text {in }}$ as the value in US dollars of direct exports in industry $i$ from country $c$ to China in year $t$.

Our indirect export data come from Smartal Solutions, the official provider of Hong Kong export statistics. These data provide Hong Kong's reported indirect exports to China, by country of origin, at the 6-digit HS level for 1996-2001. Since tariff rates vary only at the industry-year level, we generate an aggregate indirect export rate, derived by summing up exports over all countries for a given industry-year: ${ }^{5}$

$$
\text { Indirect_export_rate }_{i t}=\frac{\sum_{c} \text { Indirect_exports }_{i c t}}{\Sigma_{c}\left(\text { Indirect_exports } \text { Ict }_{i c}+\text { Direct_Exports }_{i c t}\right)}
$$

\footnotetext{
${ }^{5}$ This is to avoid complications associated with clustering of standard errors across two types of groups, as suggested by Bertrand, et al (2004). We obtain virtually identical results if the regressions are done at the exporter-year-product level of aggregation.
} 


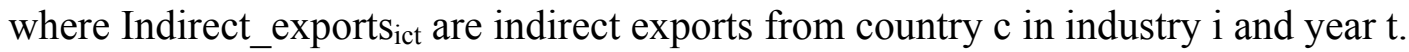

Our robustness checks will require several additional datasets; for clarity of presentation, we will describe these additional data items when we discuss these tests.

In the first two columns of Table 1 we list the Hong Kong indirect export rates and tariff rates, by year, for 1996-2001. Note that there is a high rate of indirect exports on average: 22 percent for the full sample. The average tariff rate, while 18 percent for the full sample, declined throughout the sample period, from approximately 23 percent in 1996 to 15 percent in 2001 .

In Figure 1A we show the basic relationship between tariffs and indirect export rates for 1998, where the indirect export rate shown is the average for each integer tariff rate, conditional on having at least 10 observations per tariff rate. The correlation is 0.53 , and the graph shows this positive correlation. In Figure 1B, we show the relation between the change in tariff rate during 1996-2001 and the change in indirect export rate over the same period. We see a similar pattern in this differenced relation - industries with the largest tariff declines also experienced the largest drops in indirect export rate. We now turn to the results section to examine these relations in a regression framework.

\section{Results}

\section{Benchmark Estimate}

Our basic specification is based on equation (2) above, with a year fixed effect, $\delta_{t}$, included:

(3) Indirect_export_rate ${ }_{i t}=\alpha+\beta *$ Tariff $_{i t}+\delta_{t}+\varepsilon_{i t}$

The results for specification (3) appear in Table 2. In column (1) we present the basic specification (with year fixed effects, but no industry fixed effects), and find a point estimate on Tariff of approximately 0.25 . In specification (2), we add industry-year fixed effects, with the industry defined at the 3-digit HS level. ${ }^{6}$ The slope estimate is now 0.29 . This implies that a one percentage point increase in the tariff rate leads to a 0.29 percentage point increase in the indirect export rate. We regard this as our benchmark estimate.

\footnotetext{
${ }^{6}$ Similar results are obtained with 2- or 4-digit HS level industry-year fixed effects.
} 
In terms of the economic significance of this effect, an increase in the tariff rate from zero to 19 percent (the mean tariff rate in the entire sample as reported in Table 1) leads to an increase in the indirect export rate by $19 * 0.29=5.5$ percent, all else equal. The average indirect export rate in our sample is 0.23 (Table 1). Evasion-motivated entrepôt trade thus explains almost a quarter of total indirect trade.

\section{$\underline{\text { Six-digit fixed effects and long differencing }}$}

As a robustness check, we also define an industry fixed effect at the 6-digit level (the most disaggregated level for this data set), a total of approximately 3600 fixed effects. This absorbs all between product variation in tariffs, so that any relation between tariffs and indirect export rates is being identified entirely from within-good variation in tariffs. Further, given the fact that tariffs were sometimes changed mid-year, generating identification from the year-to-year correlation between tariffs and indirect export rates may add a lot of noise. The result is reported in Column 3 of Table 2. The point estimate on tariffs declines to 0.11 , but is still significant at the one percent level..

Finally, in column (4), we consider a differenced version of specification (2), given by:

(4) (Indirect_export_rate ${ }_{i 2001}-$ Indirect_export_rate $\left._{i 1996}\right)=\alpha+\beta^{*}\left(\right.$ Tariff $_{i 2001}-$ Tariff $\left._{i 1996}\right)+\delta_{t}+\varepsilon_{i t}$

We emphasize that, relative to the fixed-effects approach, this long-differenced approach is less likely to be affected by noise resulting from the timing of tariffs and sluggish responses to tariff changes, while still absorbing all between industry variation. The point estimate is 0.17 , and is statistically significantly different zero at the one percent level.

\section{Non-linear effects}

As noted in Section 2 above, either a non-linear cost of evasion or a non-uniform distribution of firms' costs of evasion will generate a non-linear relationship between tax rates and the extent of indirect trade through Hong Kong. In Table 2, column (5) we include a quadratic term, Tariff $^{2}$, that allows for a non-linear relationship between tariffs and indirect trade. We find 
that Tariff $^{2}$ is highly significant and negative, implying a diminishing effect of increasing tariffs on indirect trade. ${ }^{7}$

\section{$\underline{\text { Aggregation }}$}

Unfortunately, because of noise the fit of the regressions may be considered poor. A common method of dealing with noisy data is aggregation. We follow this approach, using as the outcome variable the mean value of the indirect trade rate for each tax rate. There are 53 distinct tax rates, thereby yielding a total of 53 observations per year. The result is reported in column (1) of Table 3, which shows that the positive relationship between tariff level and indirect export rate remains, with an increase in the adjusted $R^{2}$ to 0.26 . In column (2), we report regression results where observations are weighted by the number of observations per tax bracket. As a final robustness check, in columns (3) and (4), we use the median (rather than mean) indirect export rate for each tariff rate as the dependent variable. These additional regressions generate results that are very similar to those reported in column 1 of Table 3.

\section{Omitted product characteristics}

One possible concern with the above results is that there may be a correlation between the goods for which middlemen have a comparative advantage in legal intermediation and the Chinese government's choice of tariff structure. It is not immediately clear whether this would lead to an overestimate or underestimate of the effect - traditional explanations of optimal tax setting focus on demand elasticities, and it is not obvious that goods routed through Hong Kong would necessarily be low demand elasticity goods. Further, one might consider demand elasticities as part of the product fixed effects. Our results above are robust to the inclusion of 6-digit fixed effects and to differencing, which implies that the results may be identified from time variation in tariff rates; this allows us to effectively net out any product characteristics that are not timevarying.

\footnotetext{
${ }^{7}$ We obtain qualitatively very similar results using a spline regression by quartiles. Aside from a non-linear cost function of evasion, and a non-uniform distribution of the evasion cost across firms, our finding can also be explained by the possibility that at the higher end of the tariff schedule, a greater fraction of tariff evasion may take the form of outright smuggling, which is not recorded in our data. This could generate the pattern that legally recorded indirect trade as a share of total trade does not rise as fast as the tariff rate at very high tariff rates. We thank Martin Feldstein for suggesting this possibility.
} 
We present a number of additional robustness checks below that try to further rule out the primary alternative explanations.

\section{$\underline{\text { Legal exemptions of tariffs }}$}

We consider the fraction of goods that enter China with tariff exemptions. One explanation for the observed relationship between tariffs and indirect export rates that does not involve any illicit behavior is that it is easier to obtain tariff exemptions by routing goods through Hong Kong, and the incentive to obtain exemptions is increasing in the tariff rate. This would then be a case of using Hong Kong middlemen to acquire legal tariff avoidance rather than illegal tariff evasion. However, if this were the case, then we would expect to see very little effect of the tariff rate on the indirect export rate for industries where very few exemptions are allowed. We use imports broken down by exemption classification taken from Chinese Customs Statistics 1998 (Economic Information Agency, 2001). ${ }^{8}$ These data are at the 8-digit HS level, which we aggregate to the 6digit level; we then calculate a measure of exemption intensity given by the ratio of the value of imports that enter China tariff-free to the total value of imports for each 6-digit category (Exemption).

In the first column of Table 4 we report a specification that includes the interaction of Exemption and Tariff. The coefficient on the interaction term is negative and significant at the 5 percent level, implying a lower sensitivity of indirect trade to tariff rates for high exemption industries.

As an alternative, we examine a subset of the sample with relatively few legal exemptions and another subset with a lot of legal exemptions. Specifically, regressions in columns (2) and (3) correspond to the sample of products below the $10^{\text {th }}$ percentile of exemption ratio (less than $16 \%$ ) and above the $90^{\text {th }}$ percentile (greater than or equal to $99.6 \%$ ) respectively. ${ }^{9}$ It is clear from these results that industries with low exemption rates are driving our results: Tariff is positive and highly significant for the sample of products below the $10^{\text {th }}$ percentile of exemption ratio, while the coefficient on Tariff is negative and insignificant for products above the $90^{\text {th }}$ percentile.

\footnotetext{
${ }^{8}$ Unfortunately, due to the very high cost of obtaining these data, we have purchased only a single year of data.

${ }^{9}$ We obtain very similar results using the $5^{\text {th }}$ and $95^{\text {th }}$ percentiles as cutoffs.
} 


\section{Differentiated versus homogeneous products}

Finally, we run tests that try to directly address specific alternative explanations based on the two traditional rationales for entrepôt trade. First, as a test of the imperfect information/ quality sorting explanation, we examine whether there is a differential correlation between tariffs and indirect trade rates for differentiated versus non-differentiated products, as classified by Rauch (1999). Feenstra and Hanson (2004) suggest that Hong Kong may play an important intermediary role for differentiated products, since such products may require quality sorting. This may be of concern if differentiated products have higher tariff rates. Note that our fixed effects and differenced models deal with this to a large extent, since product differentiation is not timevarying. To bolster our case, we further examine whether the basic cross-sectional correlation differs according to whether the incoming good is differentiated.

Rauch's classification is at the 4-digit SITC level, which we match based on the concordance in Feenstra (1996); ${ }^{10}$ we also cluster at the 4-digit SITC level to account for the coarser industry classification. In Table 5 we present results with the sample split by Rauch's classification. It turns out that the positive correlation holds for both differentiated and nondifferentiated products ${ }^{11}$. The point estimate of the slope is somewhat smaller for the homogenous products, consistent with the view that some of the indirect trade for differentiated products are not related to tariff evasion. However, if we pool the sample and include an interaction between tariff rates and a dummy variable for differentiated products, this interaction term is not significant.

\section{Adding trade volume}

Our results are unlikely explained by a motivation to save on transport costs. To see this, we note that such an explanation would require a number of steps. First, shipment size, and hence the benefits from transshipment, is positively correlated with the indirect trade ratio. Second, in order to account for the results that we report, there must be correlation between tariff rates and shipment size. One possible channel is that larger shipments are correlated with higher overall rates of trade, which in turn may be correlated with tariffs due to political economy considerations. This explanation strikes us as requiring a big stretch of imagination. Still, to try to control for this possibility, we include the fraction of the total value of trade in year $y$ accounted for by industry $i$

\footnotetext{
${ }^{10}$ The concordance is available at http://data.econ.ucdavis.edu/international/usixd/wp5515d.html.

11 The sample is smaller because the classifications for some products are ambiguous and therefore excluded.
} 
(FRACTION) in column 4 of Table 5. Trade volume is indeed correlated with the indirect trade ratio: the coefficient FRACTION is significant at the one percent level. However, the coefficient on tariff rates is completely unchanged; this is not surprising, since trade volume is uncorrelated with tariff rates.

\section{Conclusion}

This paper documents that tariff evasion is an important motivation for the widely observed phenomenon of indirect trade in world commerce by studying indirect exports to China via Hong Kong. To build a case for this interpretation, the paper computes a measure of indirect trade intensity product by product (at the HS 6-digit level) - the ratio of indirect trade to total trade - and examines whether it is systematically related to product-level tariff rates. We find clear evidence of a positive, statistically significant relationship, both in levels and differences.

A number of robustness checks and extensions of the basic analysis help to further bolster our interpretation. For example, were it not for tariff evasion, specialized knowledge by middlemen should be much less valuable for homogenous than for differentiated products. Yet we find a similar positive correlation between indirect trade and tariff rates for the two groups of products. Also, for the subset of products for which tariff exemptions are widely granted (and therefore illegal tariff evasion at the border is less profitable), there is no correlation between tariff and indirect trade intensity.

Our paper makes both conceptual and methodological contributions. We highlight the possibility that the desire to circumvent high barriers to cross-border commerce can generate a role for middlemen in international trade. Our approach could be applied to a variety of other contexts. While data on direct trade and tariffs are available for many countries, good-quality data on disaggregated indirect trade are hard to come by. Replicating the specification in this paper for other countries when relevant data become available is interesting extension for future work. This would allow for an evaluation of whether the evasion-motivated indirect trade that we document here is particularly prevalent in high-tariff, weak-governance economies. In addition, it may ultimately be possible to evaluate, for example, the extent to which different source countries are prone to tariff evasion, by comparing how the relationship between tariffs and indirect trade varies across exporting countries. We leave these topics for future research. 
Figure 1A - Correlation between tariffs and Hong Kong Indirect export rates, 1998

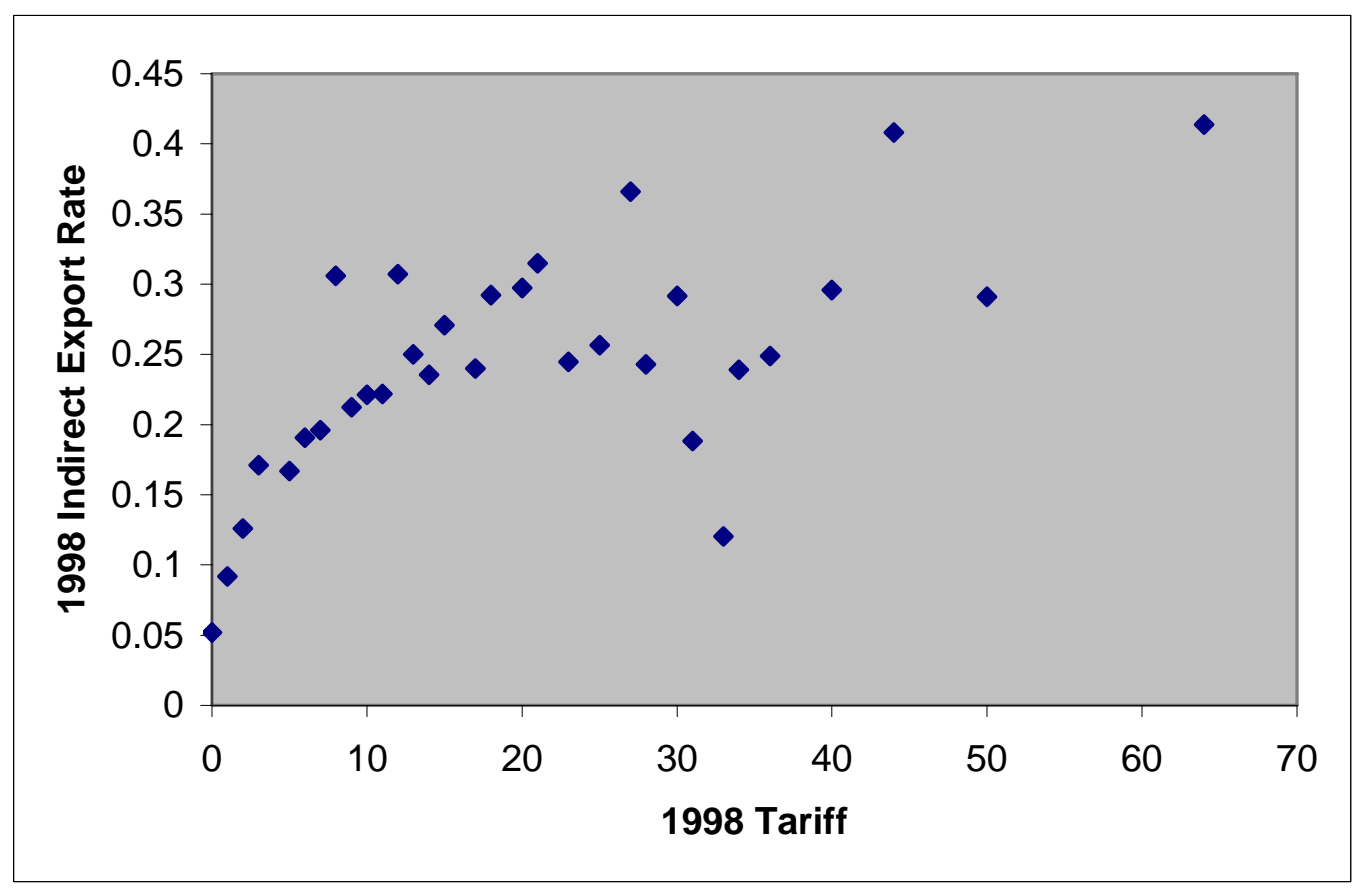

Figure 1B - Correlation between changes in tariffs and changes Hong Kong Indirect export rates, 1996-2001

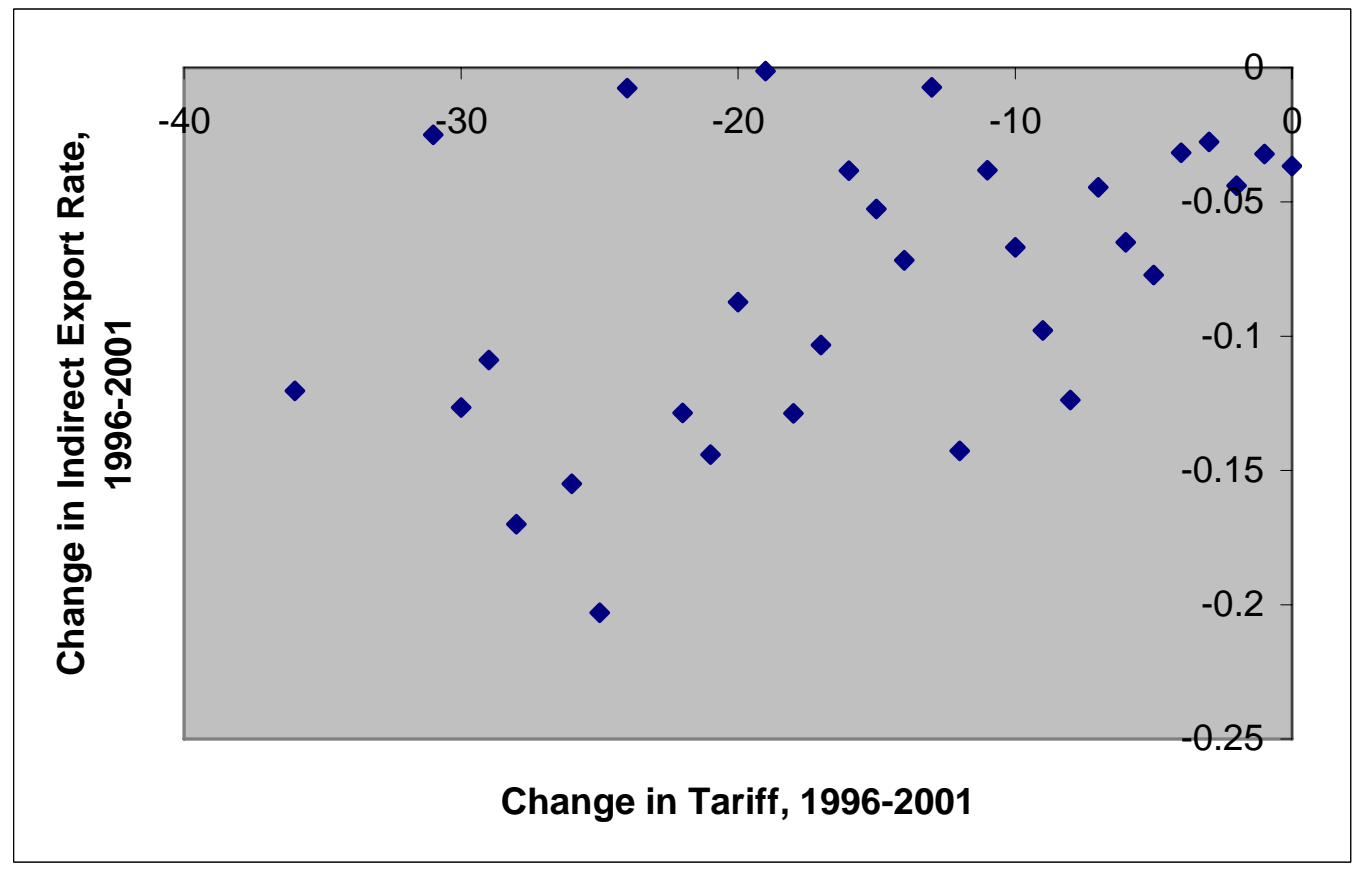


Table 1 - Indirect Export Rates and Tariff Rates

by year, 1996-2001

\begin{tabular}{ccc}
\hline & Hong Kong & \\
Year & Indirect export Rate & Chinese Tariff Rate \\
\hline 1996 & 0.260 & 0.236 \\
& $(4502)$ & $(4502)$ \\
1997 & 0.229 & 0.221 \\
& $(4537)$ & $(4537)$ \\
1998 & 0.239 & 0.175 \\
& $(4585)$ & $(4585)$ \\
1999 & 0.225 & 0.171 \\
& $(4624)$ & $(4624)$ \\
2000 & 0.218 & 0.169 \\
& $(4658)$ & $(4658)$ \\
2001 & 0.202 & 0.158 \\
& $(4671)$ & $(4671)$ \\
\hline Total & 0.229 & 0.188 \\
& $(27577)$ & $(27577)$ \\
\hline \hline
\end{tabular}

Notes: The values listed are for the sample of 29 exporting countries listed in Table A1. Numbers of observations are listed in the parentheses. For further details on the construction of the indirect export ratio, please see the text.

Table 2 - Effect of Tariff Rate on Hong Kong Indirect Export Rate

\begin{tabular}{lccccc}
\hline & $(1)$ & $(2)$ & $(3)$ & $(4)$ & $(5)$ \\
\hline Tariff & $0.250^{* * *}$ & $0.286^{* * *}$ & $0.113^{* * *}$ & & $0.705^{* * *}$ \\
& $(0.027)$ & $(0.044)$ & $(0.040)$ & & $(0.100)$ \\
$\Delta$ Tariff & & & $0.169^{* * *}$ & \\
& & & $(0.047)$ & \\
Tariff ${ }^{2}$ & & & & $-0.616^{* * *}$ \\
& & & & None & Year-Industry \\
\hline Fixed Effects & Year & Year-Industry & Year \& Industry & & $(3$-digit HS $)$ \\
\hline Observations & 27577 & 27577 & 27577 & 4411 & 27577 \\
R-squared & 0.02 & 0.17 & 0.71 & 0.00 & 0.17 \\
\hline \hline
\end{tabular}

Notes: Robust standard errors in parentheses, with clustering at the 6-digit HS level. Dependent variable in specifications (1) - (3) is Indirect_export_rate. In specification (4) the dependent variable is the five year difference in Indirect_export_rate. For further details, please see the text. $*$ significant at $10 \% ; * *$ significant at $5 \% ; * * *$ significant at $1 \%$ 
Table 3 - Aggregating the Indirect Export Rates by Tax Brackets

\begin{tabular}{lcccc}
\hline & $(1)$ & $(2)$ & $(3)$ & $(4)$ \\
& mean & mean & median & median \\
\hline \multirow{2}{*}{ Tariff } & & & & \\
& $0.262^{* * *}$ & $0.267^{* * *}$ & $0.265^{* * *}$ & $0.291^{* * *}$ \\
\hline Observations & $(0.050)$ & $(0.044)$ & $(0.079)$ & $(0.059)$ \\
R-squared & 313 & 313 & 313 & 313 \\
\hline \hline
\end{tabular}

Notes: Robust standard errors in parentheses, with clustering by tariff rate. All regressions in clued year fixed effects. Dependent variable in specifications (1) and (2) is the average value by year and tariff rate of Indirect export rate; in specifications (3) and (4) the dependent variable is the median value by year and tariff rate of Indirect export rate. Regressions (1) and (3) are unweighted, while regressions (2) and (4) are weighted by the number of observations per tariff rate. For further details, please see the text. $*$ significant at $10 \% ; * *$ significant at $5 \%$; ** significant at $1 \%$

Table 4 - Tariff-exempted versus Non-exempted Industries

\begin{tabular}{lccc}
\hline \multicolumn{1}{c}{ Sample } & Full Sample & $\begin{array}{c}\text { Exemption }<10 \text { th } \\
\text { percentile }\end{array}$ & $\begin{array}{c}\text { Exemption }>90 \text { th } \\
\text { percentile }\end{array}$ \\
\hline Tariff & $(1)$ & $(2)$ & $(3)$ \\
Exemption Rate & $0.428^{* * *}$ & $0.440^{* * *}$ & -0.174 \\
& $(0.076)$ & $(0.147)$ & $(0.220)$ \\
Exemption Rate & $\left(0.105^{* * *}\right.$ & & \\
$\quad-0.019)$ & & \\
\hline Obsariff & $(0.094)$ & & \\
R-squared & 25297 & 2526 & 2526 \\
\hline \hline
\end{tabular}

Notes: Robust standard errors in parentheses, with clustering at the 6digit HS level. All regressions include industry-year fixed effects, at the 3-digit HS level. Dependent variable in all specifications Indirect_export_rate. For further details, please see the text. * significant at $10 \% ; * *$ significant at $5 \% ; * * *$ significant at $1 \%$ 
Table 5 - Differentiated vs. Undifferentiated Products; Trade Volume

\begin{tabular}{lcccc} 
& $(1)$ & $(2)$ & $(3)$ & $(3)$ \\
\hline Tariff & $0.173 * *$ & $0.280^{* * *}$ & $0.182 * * *$ & $0.289 * * *$ \\
& $(0.084)$ & $(0.096)$ & $(0.064)$ & $(0.044)$ \\
Differentiated & & & 0.087 & \\
$*$ Tariff & & $(0.073)$ & \\
$\begin{array}{l}\text { Fraction of } \\
\text { total trade }\end{array}$ & & & $14.00 * * *$ \\
\hline \multicolumn{1}{c}{ Sample } & \multirow{2}{*}{ Undifferentiated } & Differentiated & All Products & All \\
& & & Products \\
\hline Fixed Effects & & Year-Industry (3-digit HS) & \\
\hline Observations & 6375 & 12605 & 18980 & 27577 \\
R-squared & 0.21 & 0.19 & 0.18 & 0.17 \\
\hline \hline
\end{tabular}

Notes: Robust standard errors in parentheses, with clustering at the 4-digit HS level.

Dependent variable in all specifications Re-export_ratio. For further details, please see the text. * significant at $10 \% ; * *$ significant at $5 \% ; * * *$ significant at $1 \%$ 
Table A1 - List of countries

\begin{tabular}{lc}
\hline Country & Annual Observations \\
\hline Argentina & 356 \\
Australia & 1,250 \\
Austria & 1,789 \\
Canada & 1,089 \\
Czech Republic & 645 \\
Denmark & 797 \\
Finland & 961 \\
France & 2,209 \\
Germany & 2,890 \\
Great Britain & 2,246 \\
Greece & 204 \\
Hungary & 290 \\
Indonesia & 1,292 \\
Ireland & 448 \\
Italy & 2,418 \\
Japan & 3,649 \\
Korea & 3,363 \\
Mexico & 257 \\
Netherlands & 1,453 \\
New Zealand & 426 \\
Norway & 564 \\
Poland & 107 \\
Portugal & 335 \\
Slovenia & 135 \\
Spain & 1,279 \\
Sweden & 1,390 \\
Switzerland & 1,791 \\
Turkey & 467 \\
United States & 3,569 \\
\hline & \\
&
\end{tabular}




\section{References}

Andriamananjara, Soamiely, Hugh Arce, and Michael J. Ferrantino, 2004,

"Transshipment in the United States," working paper, U.S. International Trade

Commission.

Bertrand, Marianne; Esther Duflo, and Sendhil Mullainathan, 2004,"How Much Should We Trust Differences-in-Differences Estimates?" Quarterly Journal of Economics, 119(1), pp. 249-75.

Feenstra, Robert, 1996, "U.S. Imports, 1972-1994: Data and Concordances”, NBER Working Paper 5515.

Feenstra, Robert, and Gordon Hanson, 2004, "Intermediaries in Entrepôt Trade: Hong Kong Re-exports of Chinese Goods," Journal of Economics \& Management Strategy, 13(1), Spring, 3-35.

Fisman, Raymond, and Shang-Jin Wei, 2004, "Tax Rates and Tax Evasion: Evidence from 'Missing Imports' in China," Journal of Political Economy, 2(112): 471-496, April.

Rauch, James E., 1999, "Networks Versus Markets in International Trade," Journal of International Economics 48(1) (June): 7-35.

Slemrod, Joel B., and Shlomo Yitzhaki, 2000, "Tax Avoidance, Evasion, and Administration," NBER working paper no. 7473 (January).

UNCTAD, 2005, “Trade and Development Report.” Geneva.

USDA/Foreign Agricultural Service, 1997, Attaché Reports, No. CH7610. 